\title{
The effects of solidification conditions and heat treatment on the microstructure and mechanical properties of EN-AC 44400 alloy
}

\author{
S. Mohsen Sadrossadat, Sten Johansson \\ Division of Engineering Materials, Linköping University, Sweden
}

\begin{abstract}
Keywords: solidification conditions, microstructurte, mechanical properties, intermetallics, heat treatment
\end{abstract}

\begin{abstract}
Improved mechanical and physical properties of an Al-Si alloy as a well-known casting alloy is strongly dependent upon the morphology of silicon particles, Al grains and also type of intermetallics which are in turn a function of alloy composition, solidification rate and heat treatment. This study aims at investigating the influence of the different solidification conditions (high pressure die, gradient and sand cast) and heat treatment on the microstructure (dendrite parameters, silicon particle morphology, intermetallic compounds), mechanical properties and fracture surface appearance of $\mathrm{Al}-9 \mathrm{Si}-4 \mathrm{Mn}$ alloy. To identify the features of microstructure and fracture surface analysis, a combination of optical metallography, scanning electron microscopy (SEM) and energy dispersive X-ray spectroscopy (EDS) have been employed. The results show that the cooling rate has a strong effect on the evolution of intermetallics, morphology of the silicon and dendrite parameters.
\end{abstract}

\section{Introduction:}

Aluminium alloy castings have been widely used in automobile, aerospace and other applications. Cast Al-Si alloys are common materials that have been produced and used for many industrial applications. The unique combination of different properties, such as, excellent castability and acceptable mechanical properties can be the main reason for increasing the use of this family of alloys. The mechanical properties are strongly related to their microstructures that can be changed by cooling rate and heat treatment condition. The influence of cooling rate during solidification process on the microstructure has been investigated by many researchers [1-4]. Primary dendritic arm spacing (PDAS) and secondary dendrite arm spacing (SDAS) are conventional features in the microstructure which can assist a lot to characterize the microstructure [5]. Iron based intermetallics are well known as the most common phases in Al-Si foundry alloys. They can have morphology; shape and chemical composition depending on the alloying elements present in the alloy and solidification rate of the melt. The most reported types of morphology are plate-like phase, such as, $\beta$-Al5FeSi, polyhedral and script-type phase, such as, $\alpha-\mathrm{Fe} \mathrm{Al15}(\mathrm{Fe}, \mathrm{Mn}) 3 \mathrm{Si} 2$ [6-10].

The effect of solidification rate on the amount and chemical composition of eutectic content, intermetallics and mechanical properties of $\mathrm{Al}-\mathrm{Si}$ alloys have been reviewed by many researchers[11-16]. It has been shown by some investigators that as cooling rate increases, the amount of eutectics increase which been associated with changing the composition of the eutectic mixture [17-18]. Different heat treatment process can change the mechanical properties of Al-Si alloys. The proper heat treatment process for each alloy depends on its chemical composition, microstructural features and the final needed properties [3, 19, 20 and 21].

\section{Experimental Details:}

Castings produced by sand moulds, gradient casting machine and high pressure die casting (HPDC) were the main objects for study in this work.

Casting procedure. Melting was carried out in an electric resistant furnace. The chemical composition of the alloy used in this research is listed in table 1. 
Table 1. Chemical composition of the alloy used in the experiment in $\mathrm{Wt} \%$.

\begin{tabular}{|l|l|l|l|l|l|l|l|l|l|l|l|}
\hline Alloy name & $\mathbf{S i}$ & $\mathbf{F e}$ & $\mathbf{C u}$ & $\mathbf{M n}$ & $\mathbf{M g}$ & $\mathbf{N i}$ & $\mathbf{Z n}$ & $\mathbf{S n}$ & $\mathbf{T i}$ & $\mathbf{O t h e r}$ & $\mathbf{A l}$ \\
\hline $\begin{array}{l}\text { EN44400- } \\
\text { Standard } \\
\text { alloy }\end{array}$ & $\begin{array}{l}8- \\
11\end{array}$ & 0.55 & 0.08 & 0.5 & 0.1 & 0.05 & 0.15 & 0.05 & 0.15 & 0.15 & rest \\
\hline $\begin{array}{l}\text { Investigated } \\
\text { alloy }\end{array}$ & 8.5 & 0.11 & 0.004 & 0.4 & 0.002 & 0.006 & --- & --- & --- & $\begin{array}{l}\text { Mo: } \\
0.07\end{array}$ & rest \\
\hline
\end{tabular}

Given limits are considered like maximum unless they are expressed as a range

Sand cast specimens. The oil-based red sand type was used for sand casting method. Three cylindrical shape specimens with the same dimensions $(\mathrm{d}=12 \mathrm{~mm}, \mathrm{l}=100 \mathrm{~mm})$ were made in sand moulds (SC).

Gradient cast specimens. After preparation of melt with the mentioned composition, it was first cast in a prepared copper mould to produce rod shaped specimens as a raw material for the gradient casting machine. The machine, as shown in Fig. 1, enables production of castings with a certain rate of solidification, good feeding and low content of inclusions. 3, 0.3 and $0.03 \mathrm{~mm} / \mathrm{sec}$ were different solidification rates which resulted in specimens with different PDAS and SDAS, as can be seen in table 2 .

Table 2. Dendrite arm spacing of different moulds

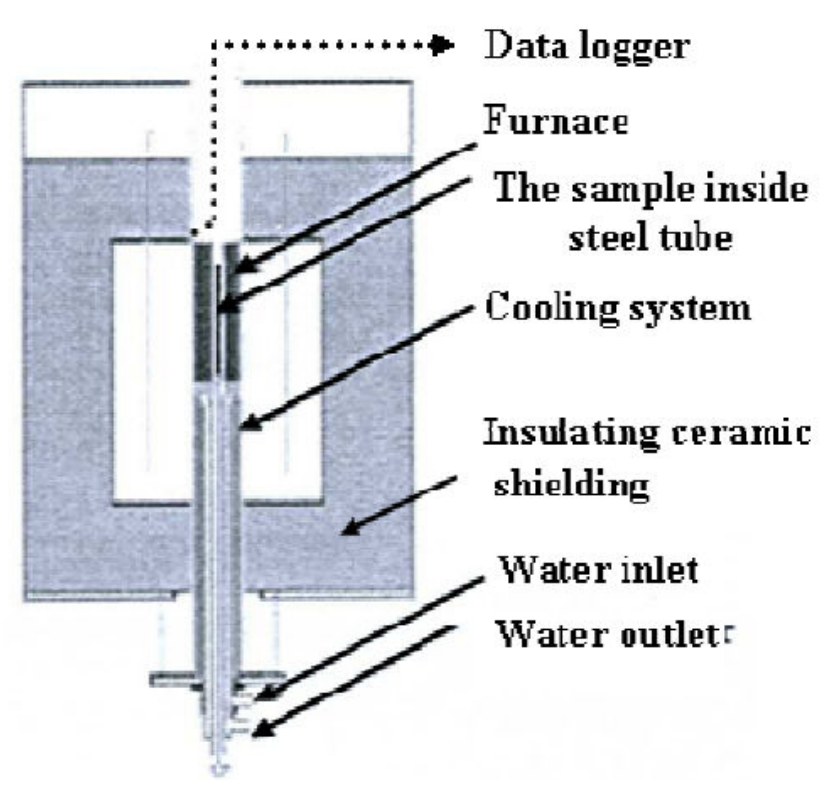

Fig. 1. Schematic of gradient casting machine

High pressure die cast components. Six high pressure die cast car door components (HC samples) produced by Ljunghall AB company in Sweden has been selected for further investigation. Four tensile types, two metallographic and three hardness test specimens were taken from each component. The mean value of every set of Table 2. Dendrite arm spacing of different moulds specimens is reported as the final result for each specimen.

Microstructural and mechanical experiments.Tensile testing was performed on the specimens using an Instron 5580 equipment. The tests were carried out according to ASTM standard method in order to measure the tensile properties. A micro hardness tester, Leco L400 was employed for measuring the hardness of different phases in the specimens. Secondary dendrite arm spacing (SDAS) was measured in an optical microscope using a MicoGOP 2000 image analyzer software. The microstructural changes were studied by optical and scanning electron microscopy (Hitachi SU-70) which has been equipped with an energy dispersive system (Oxford). The average compositions of the various phases were measured using EDS and the results reported are based on the average of approximately ten spot analyses.

Heat treatment. The applied heat treatment process for all of the samples was heating till $330^{\circ} \mathrm{C}$ for 90 minutes followed by cooling in air. 


\section{Results and discussion:}

Microstructure analysis. SEM images as shown in Fig. 2 reveal several interesting features. The evolution of $\alpha$ - Al dendrites which are becoming bigger with decreasing cooling rate from sample GC1 to GC3 can be seen in the Fig.2, a to c. This is in agreement with other investigations [11-14]. The continuity of the white small intermetallic particles in the microstructure of the sample GC1 (Fig.2, a) is much higher than for the other samples. It seems that there is a tendency for the coarser white intermetallics particles to appear in the $\alpha$-Al dendrites rather than in the eutectic region for the samples with the lower cooling rate than the corresponding cooling rate for sample GC2. This can be a sign of their formation prior to primary Al dendrites (Fig. 2, d). Presence of polyhedral shape intermetallics in almost all of the samples reveals their independence of cooling rate.
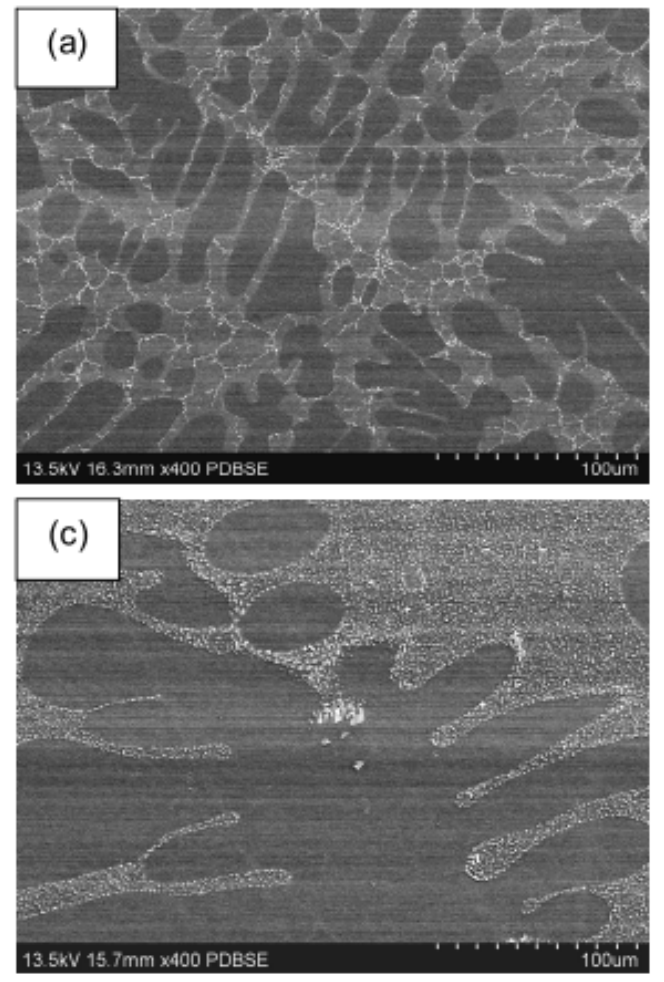
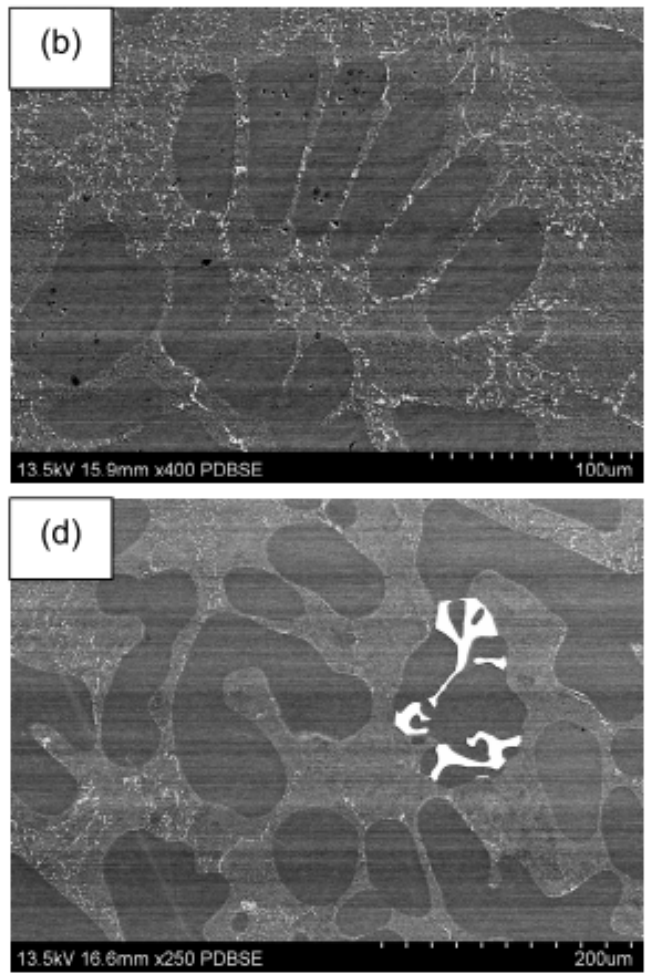

Fig. 2. SEM images showing different phases in the samples; (a) GC1, (b) GC2, (c) GC3, (d) Sand cast sample (SC)

Different types of the intermetallics and their chemical composition are given in table 3 . The mentioned table and Fig. 2 show that there is a wide variety of different intermetallic morphologies due to the different local cooling rate and the manganese is present in all of the intermetallics. This can be due to the presence of high amount of manganese in the alloy. As the table 3 shows, there is a clear tendency for molybdenum to migrate to geometrical intermetallic particles (polyhedral). The obtained results in this research are in reasonable agreement with the values reported by other researchers $[9,14]$. The main difference is the lower content of iron in the revealed intermetallics in comparison to the alloys used by other authors which can be attributed to the low amount of iron content in the investigated alloy in this study. 
Table 3. Different types of the revealed intermetallics in the samples by EDS technique

\begin{tabular}{|l|lllll|}
\hline Type of different & \multicolumn{5}{|c|}{ Chemical composition (Wt. \%) } \\
intermetallics & $\mathbf{S i}$ & $\mathbf{M n}$ & $\mathbf{F e}$ & Mo & Al \\
\hline - A type & $12-19$ & $2-4$ & $0.8-1.2$ & --- & rest \\
- B type & $4.5-5.3$ & $2.8-3.1$ & $0.11-0.2$ & 18 & rest \\
- C type & $12.2-13.5$ & $3-3.5$ & $1.4-1.6$ & --- & rest \\
- D type & $10-11.5$ & $16-21$ & $4-5$ & --- & rest \\
\hline
\end{tabular}

A type: small particles with the size between 2 to $4 \mu \mathrm{m}$ (platelet); B type: geometrical (polyhedral) particles with the size between 3-6 $\mu \mathrm{m}$; C type: needle-like particles with the composition like "A" type; D type: More complicated shape particles (star-like particles).

As can be seen in Fig. 3, the size of silicon eutectic particles is being bigger as the cooling rate decreases from sample GC2 to GC3. At the same time their shape also seems to be more rounded, as expected $[3,4]$.
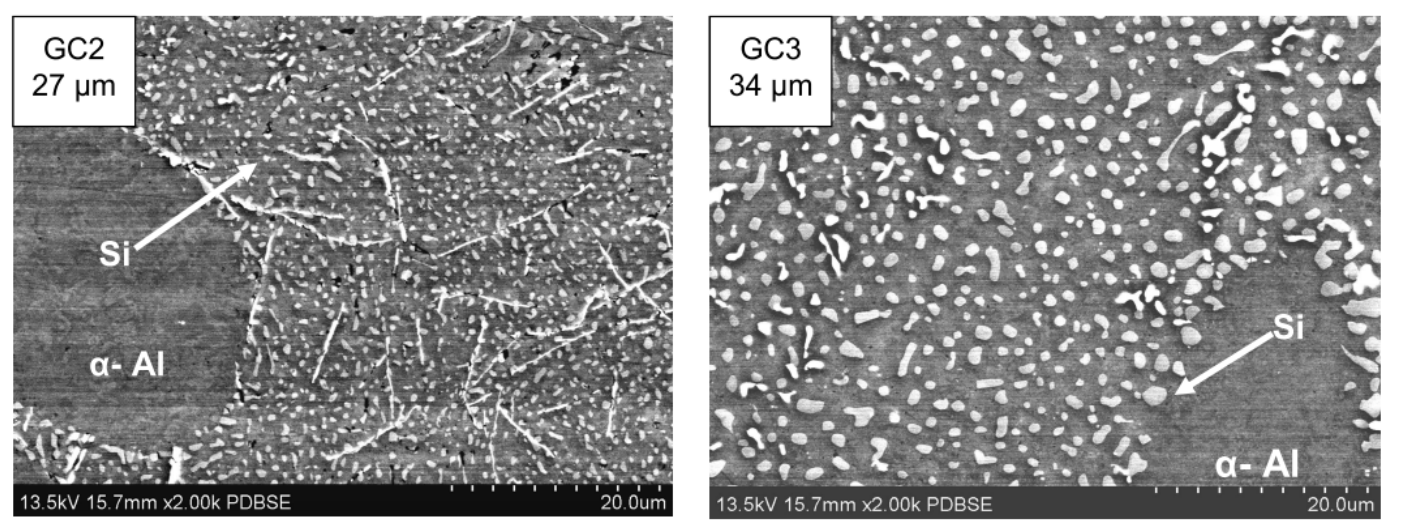

Fig.3. SEM images showing the difference of silicon eutectic particles in GC2 and GC3 samples.

As shown in Fig. 4 there is a good agreement between the PDAS and SDAS variations with cooling rate. In Fig. 5 is shown that the amount of eutectic decreases and the amount of $\alpha$-Al phase increases as the cooling rate decreases, which is in agreement with previous works [8]. The higher cooling rates can suppress or limit the nucleation of $\alpha$-Al phase.

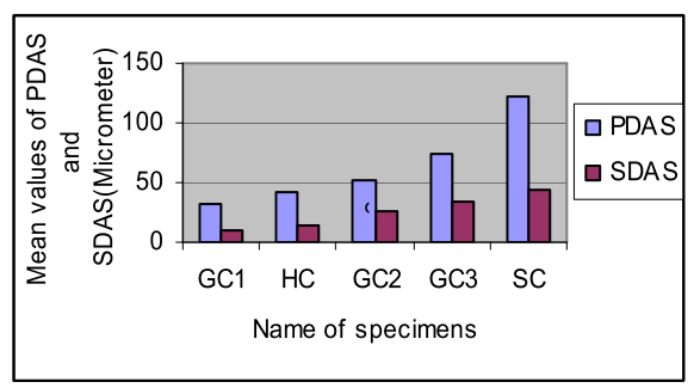

Fig. 4. Correlation between PDAS and SDAS

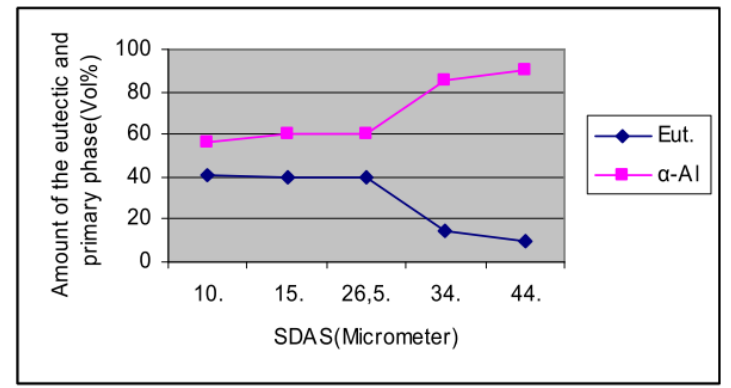

Fig. 5. Volume fraction of eutectic and primary Al phase versus SDAS

The gradient casting machine can make a variety of cooling rates correspondent to SDAS values from 10 to $49 \mu \mathrm{m}$ for this alloy, while the other methods are not so capable in that sense (Fig. 6). The relationship between SDAS and the concentration of silicon and manganese in $\alpha$-Al phase is shown in Fig. 7. A decrease in the diffusion rate at higher cooling rates can explain that change. 


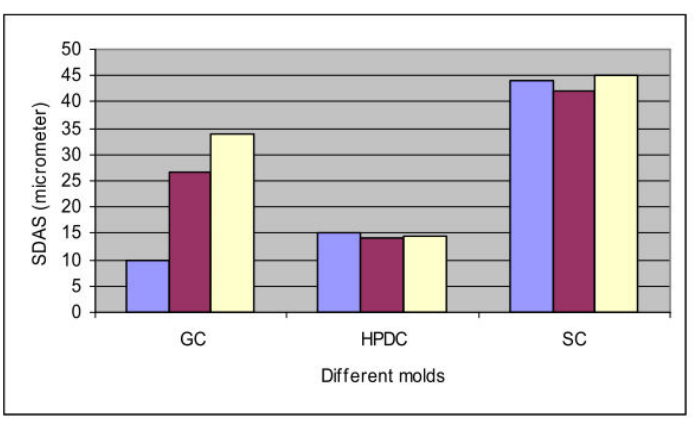

Fig. 6. SDAS values correspondence to different molds

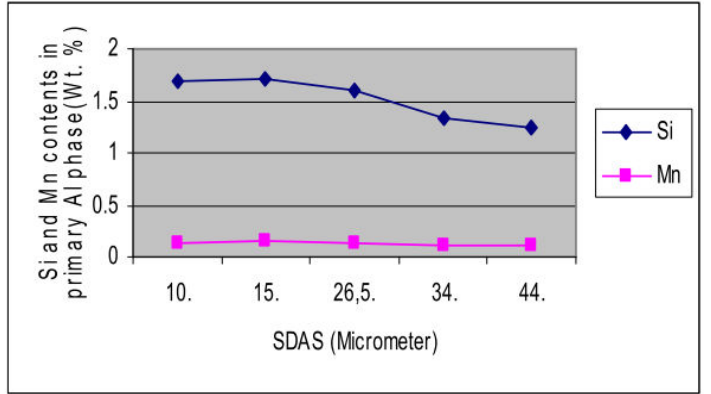

Fig. 7. The relationship between SDAS and chemical composition of $\alpha$-Al phase

Mechanical properties. The ultimate tensile strength (UTS), hardness and elongation of the samples are given in Fig. 8, a, b and c. Volume fraction changing between the eutectic and primary $\mathrm{Al}$ dendrites, changing in the size and shape of the silicon eutectic, finer $\alpha$-Al grains and presence of smaller size of intermetallics with increasing cooling rate can be the reasons for these changes. Moreover, presence of hard silicon particles in the softer $\alpha$-Al matrix plays an important role (plastic constraint) to strengthen the eutectic compound [21].

As illustrated in Fig. 8 a, the hardness numbers of the eutectic and $\alpha$-Al phase increase as SDAS decreases. Reduction of the number of hard intermetallics particles, lowering the plastic constraint effect and coarsening of silicon in eutectic are main responsible parameters for decreasing of eutectic hardness. On the other hand, a slight decrease in hardness of $\alpha$-Al phase can be due to a decrease in silicon and manganese content with increasing SDAS, as shown in Fig. 7. Both mentioned elements can have an important role in solid solution hardening of Al dendrites. All the samples show increasing elongation values with decreasing SDAS explained by better distribution of the hard (and brittle) particles that can avoid any early rupture in the samples with smaller SDAS, see figure $8 \mathrm{~b}$.

Figure $8 \mathrm{c}$, confirms that as the cooling rate increases; this is accompanied by decreasing SDAS, the UTS values increases. It can be due to an increase in volume fraction of eutectic compound, lowering the size of the silicon eutectic, decreasing the size of silicon particles within eutectic and a raise in the amount of plastic constraint. The plastic constraint increases with smaller size of silicon particles.

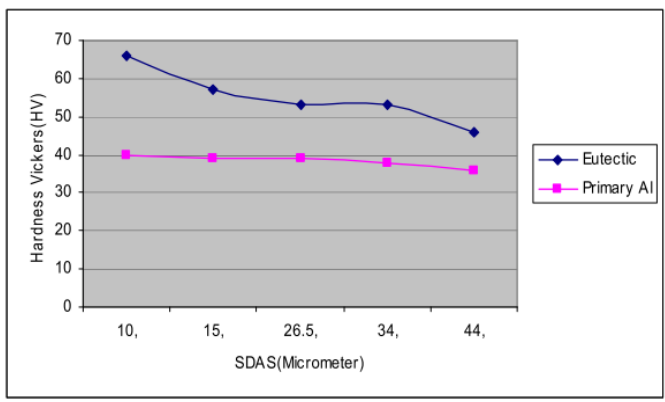

(a)

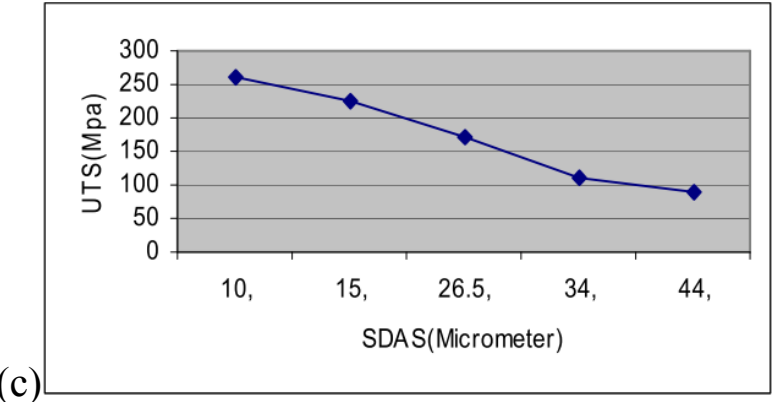

Fig. 8. Tensile properties and hardness of the samples as a function of SDAS: (a) Hardness Vickers; (b) Elongation; (c) UTS. 
Heat treatment effects. The microstructural investigations in this work didn't show any significant effects of heat treatment. On the other hand, they showed about 10\% (7-12) decrease in UTS values, nearly $14 \%(12-17 \%)$ improvement in elongation, about $6 \%$ decrease in hardness $(4-9 \%)$ and a slight difference in the silicon and manganese concentration in the phases.

\section{Conclusion}

The following conclusions can be drawn from this study of En 44000 standard alloy:

a) Continuity, size, distribution and type of the intermetallics are solidification rate dependent.

b) Cooling rate is more capable than the selected heat treatment to change the microstructure and properties of the alloy.

c) Cooling rate during solidification is able to change the priority of intermetallics formation.

d) UTS, elongation and hardness of the alloy are improved by decreasing PDAS and SDAS.

e) Eutectic volume fraction and $\alpha$-Al dendrite size variation have a greater influence than the intermetallics on the mechanical properties.

f) Gradient casting is an effective method to get a wide range of the mirostructural features and mechanical properties.

\section{Acknowledgments}

Ministry of science, research and technology of Iran, Ljunghall AB foundry company, Component technology division of Jonkoping University, Stena Aluminum AB company

\section{References}

[1]. W. F. Smith: Structure and Properties of Engineering Alloys, McGraw-Hill publication company, 2nd Edition, 1992.

[2] Q. G. Wang, C.J. Davidson: J. Mater. Sci. Vol 36 (2001), P739-750

[3] S. G. Shabestari, F. Shahri: J. Mater. Sci. Vol 39 (2004), P2023-2032

[4] Cameron M. Dennis, john A. Taylor and Arne K. Dahle: Scripta. Mater. Vol 53(2005), P 955958

[5] E. Cadirli, M. Gunduz: J. Mater. Sci. Vol 35(200) P. 3837-3848

[6] M. Warmuzek, J.Sieniawski, K.Wicher, G.Mrovka: J. Mater. Proc. Tech. Vol175 (2006) P. 421426

[7] M. A. Moustafa: J. Mater. Proc. Tech. XXX (2008) XXX-XXX

[8] M. Ozenbas, H. Guler: Chem. Comm. Vol 190(2003) P.911-924

[9] S. G. Shabestari: Mater. Sci. Eng. Vol. A383 (2004) P. 289-298

[10] M. V. Kral,P.N.H.Nakashima,D.R.G.Mitchell: Met. Mater. Trans. A Vol 37A (2006) P. 19871997

[11] L.Y. Zhang: [J. Mater. Proc. Tech. (2008)

[12] C.L. XU, H. Y. Wang: Mater. Sci. Eng. Vol. A417(2006) P. 275-280

[13] B. Dutta, M. Rettenmayer: Mater. Sci. Eng. VolA283 (2000) P. 218-224

[14] S. Seifeddine, S. Johansson, I.L. Svensson: Mater. Sci. Eng. Vol. A xxx (2008)

[15] F. Ochoa, J. J. Williams: J. Elec. Mater. Vol 32(2003)

[16] Z. Li., A. M. Samuel: Mater. Sci. Eng. Vol. A307(2004) P. 96-110)

[17] B. Closset and J. Gruzleski: AFS Transactions 89 (1981) 801

[18] 18 S. Shivkumar. R. Ricci, JR. and D. Apellian: ibid. (1990) 63-70.

[19] Metals Handbook: Heat treatment, 9th ed., Vol. 4, 1988.

[20] J. Bäckman, Licentiate Thesis no. 794, Jonkoping University, School of Engineering, 1999

[21] L. Van Vlack: Elements of Materials Science and Engineering, Adison- Wesley publication, 1989 